\title{
Avaliação de sustentabilidade em gerenciamento de projetos: um estudo exploratório no setor de alimentos
}

\author{
Mauro Luiz Martens ${ }^{\text {a** }}$, Marly Monteiro de Carvalho ${ }^{\text {a*** }}$ \\ aPRO-POLI/USP, São Paulo, SP, Brasil \\ *mauro.martens@usp.br, ***marlymc@usp.br
}

\begin{abstract}
Resumo
Apesar da difusão crescente da gestão de projetos, ainda é incipiente a discussão de temas relacionados à sustentabilidade nas dimensões ambiental, social e econômica no contexto da gestão de projetos. Este trabalho tem o objetivo de avaliar a inserção da sustentabilidade em gestão de projetos. A abordagem metodológica utilizada foi a de estudo exploratório com abordagem qualitativa, realizada em seis projetos em empresas de serviços de alimentação. Para a coleta de dados foram utilizados documentos dos projetos e entrevistas semiestruturadas com os gestores dos projetos. Como resultados apresentam-se a sistemática da ferramenta preliminar de avaliação da sustentabilidade em projetos, bem como sua aplicação prática. Conclui-se que a ferramenta proposta apresenta uma sistemática lógica e aplicabilidade para avaliar a sustentabilidade no contexto de gestão de projetos. Finalmente, os resultados da avaliação mostram que a dimensão econômica ainda se sobrepõe às dimensões ambiental e social.
\end{abstract}

Palavras-chave

Sustentabilidade. Gestão de projetos. Avaliação da sustentabilidade.

\section{Introdução}

Os cenários social, econômico e ambiental da atualidade têm forçado as organizações a inovar, gerenciar mudanças e promover o surgimento de novas atividades. Esse contexto traz novos desafios para as organizações produtivas e de serviços, os quais se apresentam de forma mais complexa e requerem maior velocidade para seu tratamento e gerenciamento (Pope et al., 2004; Wilkins, 2003). Para Dias (2009), as empresas estão sujeitas às mudanças nos valores e ideologias da sociedade e às pressões do ambiente externo à organização, que acabam por influenciar seu desempenho no mercado. Assim, cabe às organizações, além de atender às normas vigentes, apostar em processos e em recursos que sejam cada vez mais eficientes e sustentáveis, visualizando mudanças em seu ambiente competitivo calcadas na valorização das preocupações de caráter ambiental e social, além das econômicas (Borella \& Naime, 2010).
Nesse contexto emerge a necessidade de sustentabilidade. 0 conceito de sustentabilidade empresarial está ligado a três dimensões: econômica, ambiental e social, ou seja, sustentabilidade com a visão Triple-Bottom Line (Elkington, 1998; Araújo et al., 2006; Labuschagne et al., 2005; Savitz, 2006). Sob essa perspectiva, as organizações, buscando cada vez mais a excelência, são levadas a desenvolver formas de reduzir os impactos sociais e ambientais.

Uma pesquisa citada por Carvalho \& Rabechini Junior (2011) mostrou que existe uma lacuna no nível gerencial das organizações no que tange à incorporação de aspectos de sustentabilidade nos processos organizacionais. Da mesma forma, Labuschagne et al. (2005) e Carvalho \& Rabechini Junior (2011) argumentam da necessidade de as dimensões econômica, ambiental e social estarem inseridas e serem trabalhadas na função gestão de projetos visando a sustentabilidade. Essa realidade 
traz para a discussão a sustentabilidade no contexto da gestão de projetos. Segundo Silvius et al. (2013), a relação entre gestão de projetos e desenvolvimento sustentável tem despertado o interesse de profissionais e acadêmicos.

Os temas gerenciamento de projetos e sustentabilidade têm sido alvo de inúmeros estudos de forma independente, mas pouco tem sido visto sobre a convergência entre ambos. Algumas iniciativas que integram os temas já são conhecidas (Anning, 2009; Bernhardi et al., 2000; Bodea et al., 2010; Fernández-Sánchez \&Rodríguez-López, 2010; Hartig et al., 1996; Jones, 2006; Mulder \& Brent, 2006; Raven et al., 2009; Turlea et al., 2010; Vifell \& Soneryd, 2012), mas muito ainda é necessário para desenvolver ferramentas, técnicas e metodologias (Singh et al., 2012) que sejam de aplicação simples no contexto da rotina da função gestão de projetos com o intuito de inserir e avaliar a sustentabilidade no seu contexto (Cole, 2005; Carvalho \& Rabechini Junior, 2011).

A necessidade de estudos sobre a convergência dos temas sustentabilidade e gestão de projetos, aliada à crescente importância de ambos no atual contexto empresarial, motiva a realização deste estudo, que busca contribuir para o desenvolvimento da temática sustentabilidade em gestão de projetos tanto em nível acadêmico quanto na prática da engenharia de produção. Assim, esta pesquisa tem o objetivo principal de avaliar a inserção de sustentabilidade em gestão de projetos e, como objetivos específicos, desenvolver uma ferramenta de avaliação e posterior aplicação prática. A abordagem metodológica utilizada foi de pesquisa exploratória com abordagem qualitativa, por meio de pesquisa bibliográfica, pesquisa documental e análise ex-post facto de seis projetos em empresas do setor de serviços de alimentação.

Na sequência dessa introdução, este trabalho está estruturado em seis seções. Na seção 2 é apresentada a revisão da literatura do estudo. Na seção 3 discorre-se sobre a metodologia de pesquisa utilizada. A seção 4 apresenta a ferramenta preliminar de avaliação da sustentabilidade em gestão de projetos e os resultados da aplicação da ferramenta em seis projetos. Na seção 5 são tecidas as considerações finais e, por fim, apontadas as referências deste estudo.

\section{Revisão da literatura}

Nesta seção serão abordados conceitos sobre sustentabilidade e gestão de projetos, bem como a importância da relação entre os dois temas.

\subsection{Sustentabilidade}

Para iniciar o entendimento de sustentabilidade faz-se necessário abordar o conceito de desenvolvimento sustentável. De acordo com a Comissão Mundial sobre Meio Ambiente e Desenvolvimento, o desenvolvimento sustentável é aquele que atende às necessidades do presente, sem comprometer as necessidades das gerações futuras (World Comission on Environment and Development, 1987). Segundo Araújo \& Mendonça (2007), ele é sinônimo de sociedade racional, de indústrias limpas e de crescimento econômico.

Um conceito mais amplo de desenvolvimento sustentável se apoia na integração de três dimensões (econômica, ambiental e social), constituindo o tripé da sustentabilidade, conhecido como Triple-Bottom Line - TBL (Elkington, 1998). 0 conceito TBL tornou-se amplamente conhecido (Labuschagne et al., 2005; Savitz, 2006; Araújo \& Mendonça, 2009; Carvalho \& Viana, 1998; Coral, 2002; Araújo, 2010; Munck et al., 2012) e

[...] essa visão mais abrangente de sustentabilidade vem em grande medida por iniciativa e pressão da sociedade. (Carvalho \& Rabechini Junior, 2011, p. 302).

Na mesma linha colabora Oliveira Filho (2004), para quem as dimensões apontadas pelo conceito de desenvolvimento sustentável contemplam o cálculo econômico, o aspecto biofísico e o comportamento sociopolítico.

De acordo com Araújo \& Mendonça (2009) e Altenfelder (2004), os conceitos de desenvolvimento sustentável e sustentabilidade são distintos: o desenvolvimento sustentável é comumente associado à expectativa de um país que entra numa fase de crescimento que se mantém ao longo do tempo; a sustentabilidade é a capacidade de autossustentar-se e de automanter-se. A esse último conceito estão atrelados termos como desenvolvimento ou crescimento econômico, mas que seja sustentável (Santos \& Hatakeyama, 2012). Os mesmos autores argumentam que se pode relacionar desenvolvimento sustentável a políticas públicas e sustentabilidade às demais ações promovidas pelo setor privado.

Para contribuir para a sustentabilidade, as organizações devem modificar seus processos produtivos (Araújo \& Bueno, 2008), produzir de forma a não agredir o meio ambiente (Pimenta \& Gouvinhas, 2012) e isso implica construir sistemas de produção que não causem impactos negativos e oferecer produtos e serviços que contribuam para a melhoria do desempenho ambiental (Coral, 2002). Para Hubbard (2009), medir desempenho organizacional não é fácil, mesmo assim as organizações preocupadas 
com sustentabilidade estão iniciando a realização de relatórios de sustentabilidade.

Para 0’Dwyer \& Owen (2005) e Jones et al. (2005), a realização de relatórios de sustentabilidade é uma tendência, mas alguns cuidados devem ser tomados, por duas razões: a primeira porque os relatórios não são muitas vezes integrados com relatórios econômicos e são inconsistentes com a natureza holística da sustentabilidade; a segunda porque esses relatórios tendem a se concentrar em aspectos positivos. Mesmo assim, relatórios de sustentabilidade ajudam a integrar funções tipicamente isoladas da empresa, como finanças, marketing, pesquisa e desenvolvimento, de uma forma estratégica. A elaboração de relatórios de sustentabilidade abre diálogos internos que não poderiam ocorrer de outra forma (Global Reporting Initiative, 2012).

Nos relatórios de sustentabilidade, dependendo do modo como o conjunto de indicadores está estruturado, é possível fazer uma verificação cruzada em que há a confirmação da informação, especialmente no caso da sustentabilidade. Conforme Sustainable Measures (2012), os indicadores de sustentabilidade são diferentes dos indicadores tradicionais de progresso econômico, social e ambiental, pois esses medem as mudanças de um aspecto como se ele fosse inteiramente independente dos demais. No entanto, a sustentabilidade requer uma visão integrada do mundo, com indicadores multidimensionais que mostrem as inter-relações entre a economia, o meio ambiente e a sociedade.

Algumas formas para a avaliação da sustentabilidade empresarial são já conhecidas:

- 0 Dow Jones Sustainability Indexes - DJSI (2012), que tem credibilidade internacional dentre as organizações e possui o enfoque dos acionistas (shareholders), tem uma forma de questionamento clara e uma metodologia de avaliação objetiva dos indicadores propostos;

- A Global Reporting Initiative - GRI (2012), que tem alcance internacional e foca nos grupos de interesse (stakeholders), é utilizado como modelo para outros sistemas de indicadores de sustentabilidade;

- 0 Instituto Ethos (2012), amplamente reconhecido em território nacional, baseado no GRl e no Balanço Social do Instituto IBASE (Instituto Brasileiro de Análises Sociais e Econômicas), possui enfoque bastante abrangente na dimensão social.

Um dos mais utilizados é a GRl, que é um processo internacional de longo prazo, com participação ativa de múltiplas partes interessadas, cuja missão é desenvolver e divulgar as diretrizes para relatórios de sustentabilidade de aplicabilidade global. As diretrizes são utilizadas de maneira voluntária por organizações que desejam elaborar relatórios sobre as dimensões econômica, ambiental e social de suas atividades, produtos e serviços. 0 objetivo é auxiliar a organização relatora e suas partes interessadas a articularem e compreenderem suas contribuições para o desenvolvimento sustentável (Global Reporting Initiative, 2012).

A GRI foi criada em 1997 pela Coligação para Economias Ambientalmente Responsáveis (Ceres) em parceria com o Programa Ambiental das Nações Unidas (Pnuma). Foi estabelecida para elevar as práticas de relatórios de sustentabilidade a um nível equivalente às práticas de relatórios financeiros, buscando comparabilidade, credibilidade, rigor, periodicidade e legitimidade da informação. A GRI encarregou-se desse trabalho com a participação ativa de empresas, ONGs ambientais e sociais, organizações contábeis, sindicatos, investidores e demais partes interessadas no mundo inteiro (Global Reporting Initiative, 2012). No contexto mundial, segundo Ortas \& Moneva (2011), os relatórios de sustentabilidade nas linhas GRI somavam, em 2009, 4.832, sendo 10,12\% provindos da América Latina.

Segundo Bebbington et al. (2007) e Singh et al. (2012), existe ampla e reconhecida necessidade de indivíduos, organizações e sociedades de encontrarem modelos, métricas e ferramentas para articular a medida e a extensão da sustentabilidade de atividades atuais. Nesse sentido, para alcançar o progresso em sustentabilidade, o desenvolvimento de indicadores de sustentabilidade precisa ser sistematicamente monitorado, medido, quantificado e interpretado (Hardi \& Zdan, 2010). Embora muito do trabalho de pesquisa tenha sido desenvolvido na área de métricas de sustentabilidade, existe ainda muito espaço no domínio do contexto de sustentabilidade, pois para alguns países ou organizações é campo de natureza diversa e complexa (Welsch, 2005; Singh et al., 2012).

Da mesma forma, de acordo com Labuschagne et al. (2005), existe uma carência de sistemas de medição de desempenho que reconheçam a sustentabilidade nas práticas operacionais. Para eles, a sustentabilidade era pensada mais nos termos institucionais e estratégicos, sem considerar o lado econômico-operacional das atividades de manufatura apropriadamente. Poucos indicadores foram aplicados com o intuito de medir o rendimento das operações e os existentes focavam demasiadamente no lado ambiental e eram orientados basicamente ao desenvolvimento de produtos.

Com essas iniciativas de avaliação das práticas de sustentabilidade no contexto organizacional não tratando especificamente da função gestão de projetos, percebe-se que existe uma lacuna para estudos no que se refere a modelos de avaliação da sustentabilidade que sejam mais alinhados à função 
do gerenciamento de projetos, como será discutido na próxima seção.

\subsection{Gestão de projetos e sustentabilidade}

A área gestão de projetos tem assumido maior importância nas empresas, passando por um processo de transformação, organizando-se para ser capaz de dar respostas eficazes e ágeis às questões que lhe competem (Carvalho \& Rabechini Junior, 2011; Rabechini Junior et al., 2002). Essa situação tem provocado o aumento do número de empresas que estão adotando técnicas de gerenciamento de projetos (Kerzner, 2001; 2006).

0 Project Management Institute - PMI (2008) propôs o Guia dos Conhecimentos sobre a Gestão de Projetos (Project Management Body Knowledge - PMBoK), que estrutura o gerenciamento de projetos em nove áreas de conhecimentos essenciais. Além disso, estruturam cinco grupos de processo gerenciais que se inter-relacionam com as áreas de conhecimento: inicialização, planejamento, monitoramento e controle, execução e encerramento (Project Management Institute, 2008; 2012). Apesar da popularização dos guias de conhecimento na área de projetos, eles não devotam atenção especial à área de sustentabilidade.

Conforme Carvalho \& Rabechini Junior (2011), existe uma lacuna muito grande no nível gerencial das organizações no que tange à incorporação de aspectos de sustentabilidade nos processos organizacionais, a qual necessita de estudos. Da mesma forma, Labuschagne et al. (2005) e Carvalho \& Rabechini Junior (2011) argumentam que a sustentabilidade (nas dimensões econômica, ambiental e social) precisa ser inserida e trabalhada na função gestão de projetos, contribuindo assim para a sustentabilidade empresarial.
Para Shenhar \& Dvir (2007), a dimensão econômica da sustentabilidade é importante, pois remunera o capital do investidor, mas nesse contexto as dimensões ambiental e social devem ser fomentadas, por exemplo, em termos de eficiência de projetos, comprando melhor, aplicando recursos de forma eficaz, utilizando tecnologias limpas, usando energias renováveis, reduzindo o uso de combustíveis fósseis, dentre outras atitudes.

A gestão de projetos, quando envolve sustentabilidade, deve compreender a tensão entre os diferentes grupos de stakeholders e os trade-offs envolvidos (Carvalho \& Rabechini Junior, 2011). Para Rodrigues et al. (2005, p. 129-130),

[...] sustentabilidade de um empreendimento depende da gestão competente de sua complexidade natural, assim como da sua capacidade em considerar nos planos de negócio os interesses legítimos de seus diferentes stakeholders e os impactos no meio ambiente.

Assim, seguindo esta óptica de atendimento das partes interessadas, diversos quadros de variáveis de sustentabilidade já são conhecidos (Knoepfel, 2010; Labuschagne et al., 2005; Global Reporting Initiative, 2012; Instituto Ethos, 2012; Fiksel et al., 1999; Veleva \& Ellenbecker, 2001; Azapagic, 2004; Fernández-Sánchez \& Rodríguez-López, 2010; Buson et al., 2009; Savitz, 2006). Nesta pesquisa serão utilizados como base os estudos de Buson (2009) e Buson et al. (2009), que sugerem 15 variáveis de sustentabilidade baseadas nas dimensões econômica, ambiental e social e que podem ser utilizadas pelos gestores de projetos. A Tabela 1 apresenta essas variáveis.

Tabela 1. Variáveis das dimensões de sustentabilidade.

\begin{tabular}{ll}
\hline \multicolumn{1}{c}{ Dimensão } & \multicolumn{1}{c}{ Variáveis } \\
\hline \multirow{3}{*}{ Econômica } & - Estudos de impacto de custo contínuo para apoiar decisões; curvas de R01 e trade-off de custo x benefício; \\
& - Relacionamento com stakeholders e consumidores no processo; \\
& - Busca continua pela excelência e melhor qualidade; \\
& - Gestão de projetos ágil, com rápida tomada de decisão; \\
& - Prioridade da fase de projeto conceitual. \\
& - Rede de gestão de conhecimento; \\
& - Reuniões de consenso no processo de decisão e de reflexão para aprendizado com experiência e erros; \\
Social & - Líder de projetos para ensinar e obter comprometimento e disciplina efetiva; \\
& - Valores, princípios e crenças compartilhados pelos integrantes da empresa; \\
& - Controle visual do andamento de projetos. \\
\hline Ambiental & - Análise de desmontagem (disassembly); \\
& - Rastreamento pós venda (política de logística inversa); \\
& - Aplicação e reuso de tecnologias consolidadas; \\
& - Redução do consumo de energia e combustíveis no ciclo de vida do projeto e produto; \\
& - Uso de matéria-prima 3Rs (reuso, remanufatura e reciclagem), priorizando recursos naturais abundantes e renováveis. \\
\hline
\end{tabular}

Fonte: Buson (2009) e Buson et al. (2009). 
Além disso, a sustentabilidade em gestão de projetos pode ser explorada de diversas outras maneiras e as empresas que vislumbram a sustentabilidade como elemento fundamental para seus negócios e atuam com desenvolvimento e gestão de projetos devem ficar atentas aos seguintes pontos: fazer compras sustentáveis, desenvolver estrutura analítica de projetos que contemple entregas relacionadas à sustentabilidade, utilizar avaliação do ciclo de vida do produto e do projeto, realizar gestão de riscos dos empreendimentos considerando a categoria riscos ambientais e sociais, considerar na solução do projeto os elementos e tecnologias que promovam a sustentabilidade (Carvalho \& Rabechini Junior, 2011).

Pesquisa realizada por Martens et al. (2013) sobre a produção científica dos últimos 20 anos a respeito de sustentabilidade em gestão de projetos evidenciou que alguns artigos tratam do tema de sustentabilidade em gerenciamento de projetos na perspectiva do conceito do Triple-Bottom Line, no entanto, em geral de caráter exploratório, apresentando estudos de caso (Anning, 2009; Bernhardi et al., 2000; Bodea et al., 2010; Fernández-Sánchez \& Rodríguez-López, 2010; Hartig et al., 1996; Jones, 2006; Mulder \& Brent, 2006; Raven et al., 2009; Turlea et al., 2010; Vifell \& Soneryd, 2012). Os autores observaram uma concentração de artigos no setor da construção civil, embora o foco seja dimensão ambiental, com artigos ligados ao desenvolvimento de padrões de construção verde (LEED - Leadership in Energy and Environmental Design, mas também BREEAM - Building Research Establishment Environmental Assessment, Green Globes and Green Mark), como, por exemplo, Robichaud \& Anantatmula (2011), que apresentam diretrizes para um projeto de construção verde. As recomendações nesse setor de construção civil, além de contemplarem requisitos ambientais detalhados de projeto e performance dos prédios, com sistemas de avaliação e ponderação, apontam também para as questões de governança e participação das partes interessadas ao longo do ciclo de vida dos projetos. 0 estudo de Martens et al. (2013) também apontou uma carência de estudos no setor de indústria e da mesma forma não evidencia aplicações no setor industrial de alimentos ou de serviços de alimentação. Esse campo, ora trabalhado nesta pesquisa, representa um campo de estudo prático e acadêmico a ser colocado como alvo de estudos futuros.

Nessa linha de raciocínio, os estudos promovendo essa integração dos conceitos de sustentabilidade em gerenciamento de projetos, bem como sistemáticas de avaliação, se tornam cada vez mais necessários no ambiente empresarial.

\section{Metodologia}

Esta pesquisa é considerada de natureza exploratória, uma vez que pretende buscar a compreensão de determinado fenômeno (Selltiz et al., 1967). Possui também abordagem qualitativa (Bryman, 1989), procurando obter informações sobre a perspectiva dos indivíduos, bem como interpretar o ambiente em que a problemática acontece (Martins, 2011). Para compreender a inserção da temática de sustentabilidade em gestão de projetos, utilizou-se de pesquisa bibliográfica, pesquisa documental e análise ex-post facto (Gil, 2006; Martins \& Theóphilo, 2009) de seis projetos em empresas do setor de serviços de alimentação. A pesquisa ex-post facto é uma investigação sistemática e empírica na qual o pesquisador não tem controle direto sobre as variáveis independentes, porque já ocorreram suas manifestações ou porque são intrinsecamente não manipuláveis (Gil, 2006; Martins \& Theóphilo, 2009).

A pesquisa bibliográfica, cuja síntese foi apresentada na seção anterior, pautou-se nos temas sustentabilidade, gestão de projetos e na necessidade de integração dos dois temas. A partir dessa revisão de literatura construiu-se uma ferramenta para análise da inserção da temática sustentabilidade em gestão de projetos (Anexo 1), estruturada em três etapas: (a) a primeira descreve o entendimento do fluxo de informação necessário para a integração dos conceitos de sustentabilidade na função gestão de projetos, mostrando ações que surgem da correlação de grupos de processos com áreas de conhecimento em gerenciamento de projetos e, para cada ação, foram sugeridas variáveis ou questionamentos que, quando questionadas, devem ser relacionadas às dimensões econômica, ambiental e social; (b) a segunda etapa mostra a estruturação da ferramenta em planilha do software Excel, evidenciando etapas, fases, ações e variáveis ou questionamentos para coleta de dados dos projetos em análise, apresentando uma tabulação matemática e gráfica; (c) a terceira etapa apresenta a importância da interpretação dos resultados e a necessidade da tomada de ação pelos responsáveis pelos projetos em análise.

A amostra foi selecionada por acessibilidade e conveniência (Gil, 2006) e foi composta por seis projetos, cada um em uma empresa distinta, que constituíram as unidades de análise da pesquisa (Yin, 2005). A escolha por conveniência dos seis projetos se deu pelo acesso facilitado do pesquisador aos responsáveis pelos projetos das empresas, pelo fácil 
acesso aos documentos dos projetos e por ter participado indiretamente dos projetos via coordenação pela empresa de consultoria. Essas empresas, anteriormente à pesquisa, participaram de um projeto específico, reunidas em um programa desenvolvido em uma parceria entre o SEBRAE (Serviço de Apoio às Micro e Pequenas Empresas) do Rio Grande do Sul e uma empresa de consultoria de gestão empresarial com sede no sul do Brasil.

Os projetos alvo da pesquisa ex-post facto eram de empresas do setor de serviços de alimentação, com foco em melhoria de desempenho de unidades como açougues, mercados, e padarias. Essa melhoria envolvia mudanças nas estruturas físicas, adequação à legislação específica do setor, adequação de processo produtivo, adequação da gestão de recursos humanos e gestão financeira. As empresas executoras desses projetos são de micro e pequeno porte e os projetos foram desenvolvidos entre julho de 2005 e julho de 2007.

A análise ex-post facto dos projetos pautou-se na documentação dos projetos e em entrevistas com os gestores desses projetos. Foram analisados os diagnósticos iniciais, os orçamentos e os relatórios finais dos projetos, o que se deu em três momentos: antes das entrevistas (com o intuito de melhorar o entendimento dos projetos), durante as entrevistas (com o intuito de direcionar e minimizar o viés das respostas dos gestores dos projetos para aplicação do Anexo 1) e após as entrevistas (com o intuito de confrontar as respostas e aplicação do Anexo 1). Foram conduzidas entrevistas semiestruturadas com os gerentes/coordenadores dos projetos das empresas e com o responsável pela empresa de consultoria de gestão empresarial. A entrevista e a análise de documentos servem como fontes de evidências do estudo (Yin, 2005) além de, segundo Martins (2011), serem formas de capturar a complexidade dos casos estudados.

As entrevistas foram guiadas utilizando-se o Anexo 1, que compreende questões fechadas do tipo escala Likert nos diferentes grupos de processos da gestão de projetos, buscando evidenciar relação com sustentabilidade, além da análise paralela dos documentos dos projetos específicos e ligação com o modelo de Buson (2009) e Buson et al. (2009). As respostas das entrevistas permitiram compor uma grade relativa a cada projeto e, assim, avaliar a inserção de sustentabilidade nos projetos segundo a ferramenta desenvolvida e utilizada neste estudo. Os resultados foram tabulados, interpretados e após foi verificada sua aderência aos objetivos desta pesquisa. Para manter o sigilo das informações apresentadas e preservar a identidade das organizações, os projetos foram referidos como pro1 até pro6.

\section{Discussão dos resultados}

Nesta seção será inicialmente apresentada a ferramenta para avaliação da sustentabilidade em projetos utilizada neste estudo, que está dividida em etapa inicial (entendimento), etapa intermediária (avaliação e tabulação) e etapa final (interpretação e ações corretivas). Na sequência serão apresentados os resultados da análise de sustentabilidade nos seis projetos da amostra, bem como uma análise cruzada dos mesmos.

\subsection{Apresentação da ferramenta}

\subsubsection{Etapa inicial - entendimento}

$\mathrm{Na}$ etapa inicial, o foco da estruturação da ferramenta é a função de gerenciamento de projetos que está geralmente localizada no centro da estrutura organizacional (nível gerencial), mas também um tanto fora das fronteiras da organização, evidenciando uma posição onde a função de gestão de projetos necessita fazer o elo de ligação entre os stakeholders internos e externos à organização (Figura 1).

Já a visão genérica do fluxo de informações adequado para que ocorra a incorporação dos conceitos do tripé da sustentabilidade (Elkington, 1998) nas organizações deve ser um fluxo de informação horizontal e vertical. Em gestão de projetos, pode ser entendido como o fluxo de informações que permeia o conjunto de grupos de processos e áreas de conhecimento em gerenciamento de projetos (Project Management Institute, 2008) (Figura 2).

Nesse sentido, decompondo a função de gestão de projetos em seus grupos de processos, pode

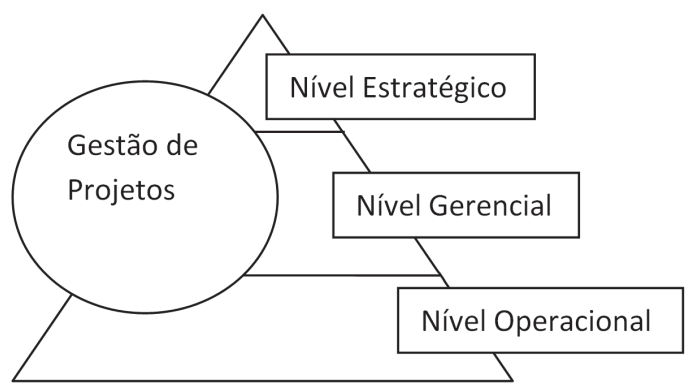

Figura 1. Gestão de projetos no contexto organizacional. Fonte: elaborado pelos autores. 


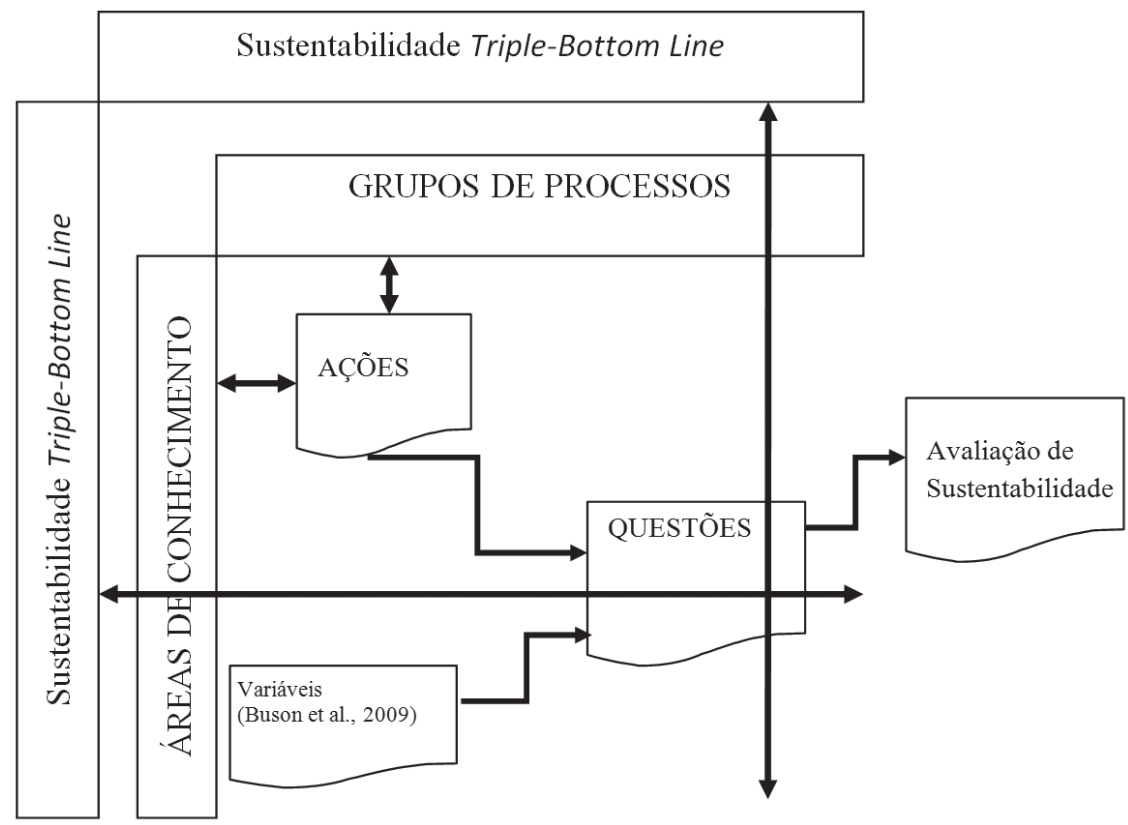

Figura 2. Representação do fluxo de informações da proposta de ferramenta preliminar de avaliação da sustentabilidade em projetos. Fonte: elaborada com base em Project Management Institute - PMl (2008), Elkington (1998), Buson et al. (2009), Global Reporting Initiative - GRI (2012), Instituto Ethos (2006), Carvalho \& Rabechini Junior (2011), Labuschagne et al. (2005).

ser visualizado e entendido que as dimensões de sustentabilidade permeiam as ações, sendo o sentido do seu fluxo de informações. Emprega-se uma adequação do relacionamento entre áreas e processos proposto pelo PMl (Project Management Institute, 2008), mas evidenciando o fluxo de informação TBL.

Partindo das ações de sustentabilidade identificadas no relacionamento entre os grupos de processos e as áreas de conhecimento em gestão de projetos, bem como da aplicação dos conceitos de sustentabilidade dentro de cada ação, pode-se traçar a avaliação da sustentabilidade nos projetos. Essa visão de medição da sustentabilidade por meio das variáveis ou questionamentos a respeito da sustentabilidade em gerenciamento de projetos é representada nos relacionamentos da Figura 2.

\subsubsection{Etapa intermediária - avaliação e tabulação}

Nesta etapa da proposta de ferramenta de avaliação de sustentabilidade em gestão de projetos serão apresentadas as variáveis ou questionamentos para cada ação resultante do relacionamento entre grupos de processos e áreas de conhecimento em gerenciamento de projetos.

Essas variáveis das dimensões de sustentabilidade serão avaliadas para cada projeto individualmente.
Em cada questão será reportada a condição de avaliação segundo escala do tipo Likert de cinco pontos, onde as notas representam: (1) não observância; (2) observância baixa; (3) observância média; (4) observância alta; (5) total observância; (N/A) não se aplica.

A ferramenta de avaliação da sustentabilidade em projetos é composta por três etapas e cinco fases (grupos de processos: iniciar o projeto, planejar o projeto, executar o projeto, monitorar e controlar o projeto e encerrar o projeto). 0 relacionamento entre grupos de processos e áreas de conhecimento em gerenciamento de projetos (integração, escopo, tempo, custos, qualidade, recursos humanos, comunicação, riscos e aquisições) resulta em um conjunto de 22 ações. Em cada uma das 22 ações busca-se evidenciar os conceitos do tripé da sustentabilidade (Elkington, 1998) através de 85 variáveis ou questionamentos constituídos com base em Project Management Institute - PMI (2008), Buson (2009), Buson et al. (2009), Coral (2002), Global Reporting Initiative (2012), Instituto Ethos (2006), Carvalho \& Rabechini Junior (2011), Labuschagne et al. (2005), para evidenciar elementos de sustentabilidade quando relacionados às dimensões econômica, ambiental e social (Elkington, 1998; Buson et al., 2009). No Anexo 1 pode ser evidenciada a ferramenta de avaliação, com toda a listagem dos questionamentos ou variáveis utilizados em cada ação nas devidas fases do projeto ou grupos 
de processos. A Tabela 2 apresenta apenas um exemplo dessa relação, mostrando a fase de encerrar o projeto.

Nesta etapa da proposta de ferramenta de avaliação da sustentabilidade em projetos é exposta uma tabela de avaliação utilizando o software Excel, conforme exemplo da Tabela 2 que apresenta a análise do projeto pro1 para o grupo de processos de encerramento do projeto da área de conhecimento gestão da integração. Para cada variável ou questionamento de sustentabilidade, a partir da escala Likert, é pontuada uma nota percentual por dimensão do TBL (ver Equação 1) e, após, o total percentual das três dimensões do grupo de processo ou fase da ferramenta em relação ao alinhamento à filosofia sustentável no projeto (ver Equação 2). 0 Anexo 1 apresenta a ferramenta completa para o projeto pro 1.

Para melhor entendimento das equações, foi utilizada a seguinte notação:

Escala likert: $\mathrm{e}=\{1,2,3,4,5\}$

Dimensão: $\mathrm{i}=\{$ Econômica,Ambiental,Social $\}$

Fase: $\mathrm{j}=\{$ Inicar Projesto,Planejar Projeto,.... $\}$

Projeto: $k=\{1,2,3, \ldots\}$

Variáveis: $\mathrm{z}=\{1,2,3, \ldots\}$

$X_{z e j i k}:$ Nota da variável na escala da dimensão

fase projeto

$W_{z i j}$ : Peso da variável na dimensão fase $n_{z j}$ : Número de variáveis na fase

$n_{e}$ : Quantidade de escalas

$n_{i}$ : Quantidade de dimensões

$n_{j}$ : Quantidade de fases do projeto

$\% T B L_{\text {eijk }}: \% T B L$ da escala na dimensão fase do projeto

$\% T_{B L}$ : \%TBL da dimensão fase do projeto

$\% T B L_{j k}: \%$ TBL da fase do projeto

$\% T B L_{i k}$ : \%TBL da dimensão do projeto

$\% T_{B L}$ : \%TBL do projeto

$\% T B L_{e i j k}=\frac{\sum_{z=1}^{n_{z i j}} X_{z e i j k} \cdot W_{z i j}}{n_{z j}} \cdot 100 \%$

$\% T B L_{i j k}=\frac{\sum_{e=1}^{n_{e}} \% T B L_{e i j k}}{n_{e}}$

$\%_{T B L}=\frac{\sum_{j k}^{n_{i}} \% T B L_{i j k}}{n_{i}}$

$\% T B L_{i k}=\frac{\sum_{j=1}^{n_{j}} \% T B L_{i j k}}{n_{j}}$

$$
\% T B L_{k}=\frac{\sum_{i=1}^{n_{i}} \% T B L_{i k}}{n_{i}}
$$

Tabela 2. Avaliação das variáveis das dimensões de sustentabilidade do projeto pro1: grupo de processos de encerramento e área de gestão da integração (exemplo).

\begin{tabular}{|c|c|c|c|c|c|c|c|c|c|c|c|c|c|c|c|c|c|c|c|}
\hline \multirow{2}{*}{$\frac{\text { FASE }}{\text { AÇÃO }}$} & \multirow{2}{*}{$\begin{array}{c}\text { ENCERRAR O PROJETO } \\
22 \text { TERMO DE ENCERRAMENTO }\end{array}$} & \multicolumn{6}{|c|}{ Dimensão econômica } & \multicolumn{6}{|c|}{ Dimensão ambiental } & \multicolumn{6}{|c|}{ Dimensão social } \\
\hline & & 1 & 2 & 3 & 4 & 5 & N/A & 1 & 2 & 3 & 4 & 5 & N/A & 1 & 2 & 3 & 4 & 5 & N/A \\
\hline 79 & $\begin{array}{c}\text { Confirmar se os trabalhos técnicos } \\
\text { acabaram e se os resultados atendem } \\
\text { ao escopo. }\end{array}$ & & & & & 1 & & & 1 & & & & & & 1 & & & & \\
\hline 80 & $\begin{array}{l}\text { Obter aceitação formal dos resultados } \\
\text { finais do projeto. }\end{array}$ & & & & & 1 & & & & 1 & & & & & & 1 & & & \\
\hline 81 & $\begin{array}{l}\text { Reportar a conclusão do projeto na } \\
\text { última reunião de acompanhamento. }\end{array}$ & & & & & 1 & & & 1 & & & & & & 1 & & & & \\
\hline 82 & $\begin{array}{l}\text { Organizar o diretório de documentos } \\
\text { do projeto para futuras consultas. }\end{array}$ & & & & 1 & & & 1 & & & & & & & 1 & & & & \\
\hline 83 & $\begin{array}{c}\text { Identificar e documentar lições } \\
\text { aprendidas. }\end{array}$ & & & 1 & & & & & 1 & & & & & & 1 & & & & \\
\hline 84 & $\begin{array}{l}\text { Liberar o produto ou serviços para as } \\
\text { operações da empresa. }\end{array}$ & & & & 1 & & & & 1 & & & & & & 1 & & & & \\
\hline 85 & Liberar a equipe do projeto. & & & & 1 & & & & 1 & & & & & & & 1 & & & \\
\hline & $\begin{array}{l}=\text { Somatório variáveis } \times \text { peso } \times 100 / n \\
\text { variáveis }\end{array}$ & 0 & 0 & 42,9 & 171 & 214 & 0 & 14,3 & 143 & 42,9 & 0 & 0 & 0 & 0 & 143 & 85,7 & 0 & 0 & 0 \\
\hline & \% Total da dimensão & & & 85,7 & 142 & & & & & 40 & & & & & & 45,71 & & & \\
\hline & Total da dimensão TBL na FASE & & & & & & & & & 57,14 & & & & & & & & & \\
\hline & \% Total da dimensão & & & 60,5 & 834 & & & & & 30,20 & & & & & & 32,56 & & & \\
\hline$\% \mathrm{TC}$ & $\begin{array}{l}\text { TAL DE SUSTENTABILIDADE TBL NO } \\
\text { PROJETO }\end{array}$ & & & & & & & & & 41,11 & & & & & & & & & \\
\hline
\end{tabular}

Fonte: elaborada pelos autores. 
A Equação 3 refere-se a média das dimensões econômica, ambiental e social dentro de cada fase de projeto. Ao final é calculada a média das notas percentuais de cada uma das cinco fases ou grupos de processos (ver Equação 4), bem como é calculada a média geral de alinhamento ao Triple-Bottom Line de todas as cinco fases da ferramenta (ver Equação 5). Após estes resultados são tabulados e visualizados graficamente.

Ao final é calculada a média das notas percentuais de cada uma das cinco fases ou grupos de processos, bem como é calculada a média geral de alinhamento ao Triple-Bottom line de todas as cinco fases da ferramenta (ver Equação 3). Após, esses resultados são tabulados e visualizados graficamente.

\subsubsection{Etapa final - Interpretação e ações corretivas}

A última etapa da ferramenta preliminar de avaliação de sustentabilidade em projetos versa sobre interpretações e tomada de ações corretivas. Destaca-se a importância da interdependência e comprometimento dos participantes do projeto em todas as fases do ciclo de vida do projeto. Vale destacar que com a análise ex-post facto dos projetos, o potencial de análise de ações corretivas é limitado, mas a discussão dos resultados em avaliações parciais pode maximizar os resultados finais em sustentabilidade.

A ferramenta proposta propicia duas formas de condução das interpretações das avaliações realizadas. Na primeira forma, o gestor do projeto pode utilizar a ferramenta para avaliar as ações em qualquer ponto da cronologia do projeto. A segunda forma é o gestor utilizar a avaliação ao final do projeto para benchmarkingcom outros projetos da organização.

Com a tabulação dos dados, o objetivo é oferecer ao gestor do projeto e à equipe a possibilidade de constantemente poder questionar as ações (Argyris, 1992) relacionadas aos grupos de processo nas áreas de conhecimento. Esse questionamento leva ao aprendizado contínuo pessoal e coletivo (Senge, 1999). Senge (1999) ainda argumenta que nas organizações as pessoas aprendem mais rapidamente quando têm uma verdadeira noção de responsabilidade por suas ações. Isso encaminha ao fechamento do ciclo PDCA da qualidade (Campos, 1994; Associação Brasileira de Normas Técnicas, 2008), requerendo na etapa do "action" que a equipe seja crítica para retroceder ou avançar no projeto, tomando as ações legíveis.

Para o uso sistemático dessa ferramenta de avaliação, os responsáveis por conduzir a avaliação devem ser preparados, treinados e devem ser independentes, conforme a ISO 19011 (Associação Brasileira de Normas Técnicas, 2002). Esses avaliadores não devem avaliar suas próprias tarefas enquanto estiverem atuando nos projetos em análise.

\subsection{Análise cruzada da avaliação dos projetos}

A aplicação da ferramenta em seis projetos propiciou a verificação de sua aplicabilidade para a avaliação de sustentabilidade em gestão de projetos. Da mesma forma, possibilitou verificar a inserção da sustentabilidade nos projetos.

Realizando a avaliação de acordo com o Anexo 1, em cada um dos seis projetos, obtiveram-se os resultados individuais de cada projeto, conforme apresentado na Figura 3.

Nessa figura podemos evidenciar o nível de incorporação de sustentabilidade em gestão de projetos nas fases ou grupos de processos. No projeto pro 1, a fase encerrar o projeto apresentou $61 \%$ de alinhamento TBL e percentual total TBL de 41,3\%. No projeto pro2, a fase encerrar o projeto apresentou 67\% de alinhamento TBL e percentual total TBL de $45 \%$. No projeto pro3, a fase encerrar o projeto apresentou 59\% de alinhamento TBL e percentual total TBL de $47 \%$, mas a fase de executar o projeto teve pontuação significativa de 53\% de alinhamento TBL. No projeto pro4, a fase encerrar o projeto apresentou 54\% de alinhamento TBL e percentual total TBL de 39\%. No projeto pro5, a fase encerrar o projeto apresentou 56\% de alinhamento TBL e percentual total TBL de 38\%. Por fim, no projeto pro6, a fase encerrar o projeto apresentou $52 \%$ de alinhamento TBL e percentual total TBL de $32 \%$.

Com esses resultados pode ser verificado que o grupo de processo ou fase de planejar o projeto mostra menor esforço em sustentabilidade, apresentando 32\% de alinhamento TBL. Já a fase ou grupo de processo encerrar o projeto é onde se verifica mais esforços em sustentabilidade, com $56,19 \%$ de alinhamento TBL. Isto mostra um ponto importante a ser tratado em trabalhos e pesquisas futuras, pois o grupo de planejamento de projetos necessita de cuidados no que tange à incorporação das variáveis de sustentabilidade na concepção dos projetos e como anteriormente ensaiado por Buson (2009) e Buson et al. (2009).

A partir dos resultados mostrados na Figura 4 pode-se perceber que a média geral da sustentabilidade percebida nos seis projetos foi de $41 \%$. Além disso, a dimensão melhor avaliada foi a dimensão econômica, com 61\%, o que pode ser verificado na Figura 5. 


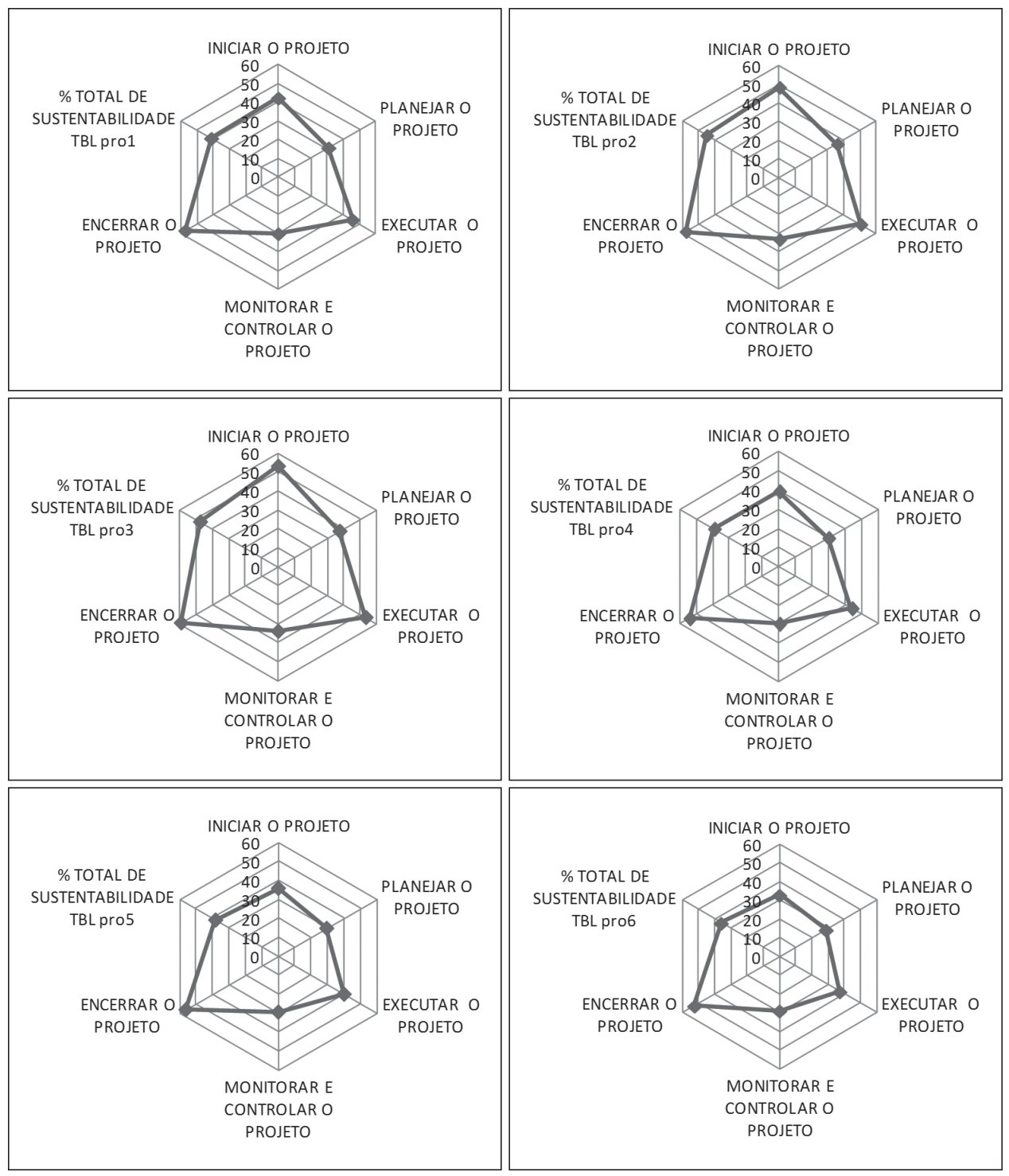

Figura 3. Resultados da avaliação da sustentabilidade por grupos de processos. Fonte: elaborada pelos autores.

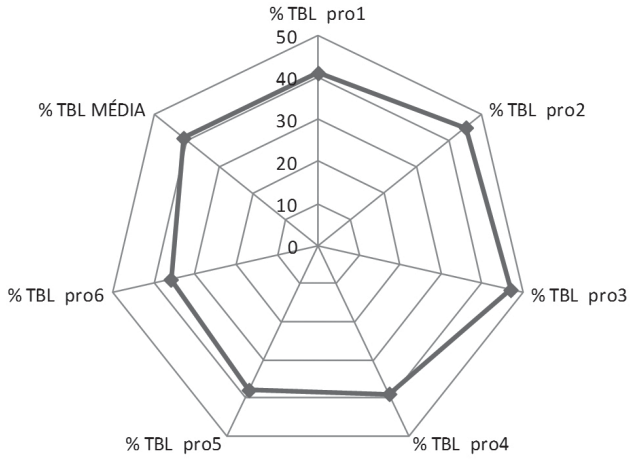

Figura 4. Resultados gerais da avaliação da sustentabilidade nos projetos da amostra. Fonte: elaborada pelos autores.
Essas respostas mostram que de fato essas empresas atuam com certo alinhamento da dimensão econômica da sustentabilidade em seus processos. Segundo comentado pelo responsável pelo projeto pro1 “...isso pode ser entendido como verdadeiro a partir de uma realidade empresarial voltada à sobrevivência em termos econômicos no ambiente das micro e pequenas empresas". Já as dimensões ambiental e social (30\% em média) são pouco expressivas em projetos, uma vez que os recursos para investimento na incorporação das dimensões ambiental e social em projetos são de difícil alocação (Labuschagne et al., 2005). 


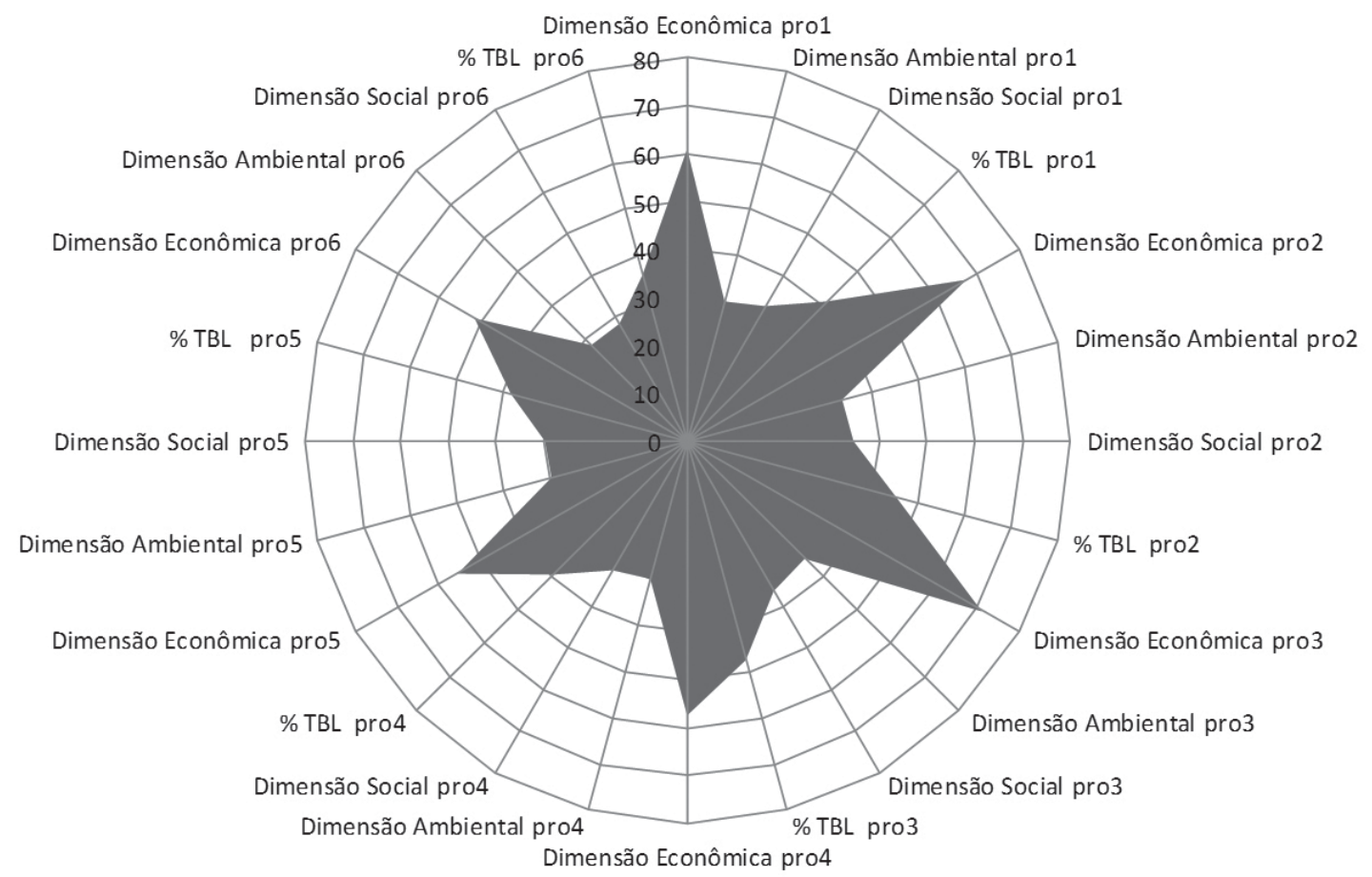

Figura 5. Resultados por dimensão de sustentabilidade nos seis projetos avaliados. Fonte: elaborada pelos autores.

\section{Conclusões}

A discussão dos conceitos centrais da pesquisa, a sustentabilidade, a gestão de projetos e a integração entre os temas, mostrou que de fato os temas apresentam-se expressivos na atualidade e merecem atenção dos pesquisadores. Outra questão é a necessidade da inserção dos conceitos de sustentabilidade com visão tridimensional Triple-Bottom Line nas práticas de gerenciamento de projetos.

Motivada por essa necessidade, a presente pesquisa objetivou analisar a inserção de sustentabilidade em gestão de projetos por meio do desenvolvimento de uma ferramenta preliminar de avaliação da sustentabilidade em gerenciamento de projetos, com base em análise de literatura sobre os temas e posterior aplicação em seis projetos desenvolvidos em empresas de serviços de alimentação via pesquisa ex-post facto. Com a linha conceitual estudada foi possível organizar as ideias citadas no texto, apresentar a proposta preliminar e avaliar os projetos, atendendo assim aos objetivos geral e específicos propostos.

Com a aplicação da ferramenta preliminar para avaliar inserção dos conceitos de sustentabilidade em seis projetos e com os resultados obtidos, concluiu-se que os projetos avaliados não tiveram resultado satisfatório em termos de sustentabilidade, ou seja, não foi evidenciado um nível adequado de ações e práticas ou indicadores de sustentabilidade econômica, ambiental e social na gestão dos projetos da amostra pesquisada.

Contudo, a aplicação da ferramenta, mesmo tendo como limitação o fato de que as variáveis ou questionamentos utilizados não foram ainda validados, apresentou aplicabilidade para a avaliação da sustentabilidade, bem como as métricas e variáveis propostas para coleta das respostas apresentaram alinhamento às práticas organizacionais. Com isso considera-se a ferramenta preliminar de avaliação de sustentabilidade em gestão de projetos aplicável para seu propósito.

Fica evidente a necessidade de continuar os esforços iniciados neste estudo no sentido de alinhar os conceitos de sustentabilidade e gestão de projetos, bem como a de refinar a ferramenta preliminar aqui proposta para avaliar a inserção de sustentabilidade em projetos. Assim, a replicação da ferramenta em outras amostras de projetos em organizações de médio e grande porte, nacionais ou internacionais, e em amostras representativas, pode contribuir para o aprimoramento e validação da ferramenta de avaliação. Adicionalmente, recomenda-se a realização de pesquisas que proponham a validação das variáveis ou questionamentos para extrair ações 
de sustentabilidade. São recomendados estudos em profundidade, no formato de estudos de casos, para melhor compreender a realidade vivenciada pelas organizações, bem como estudos tipo survey no setor de alimentos, tanto em serviços como no setor industrial, sobre sustentabilidade em gestão de projetos.

Outra limitação da pesquisa é a escolha dos seis projetos por acessibilidade e conveniência (Gil, 2006) uma vez que é o tipo de amostragem menos rigoroso, mas que de alguma forma representa o universo.

Por fim, os resultados deste estudo confirmam a necessidade de continuar os esforços em discutir os temas gestão de projetos e sustentabilidade no âmbito gerencial ou organizacional, uma vez que, por estudos já realizados, percebe-se que a inserção dos conceitos de sustentabilidade no contexto da gestão de projetos pode resultar em projetos cada vez mais sustentáveis, na óptica de produto, processo e tecnologia. Dessa forma, com produtos, processos e tecnologias sustentáveis, as organizações tendem a obter cada vez mais vantagens competitivas, tornando-se mais sustentáveis econômica, ambiental e socialmente.

\section{Referências}

Altenfelder, R. (2004). Desenvolvimento Sustentável. Gazeta Mercantil, A3(6).

Anning, H. (2009). Case Study: Bond University Mirvac School of Sustainable Development Building, Gold Coast, Australia. Journal of Green Building, 4(4), 39-54. http://dx.doi. org/10.3992/jgb.4.4.39

Araújo, G. C., \& Bueno, M. P. (2008). Um estudo sobre a sustentabilidade empresarial na agroindústria frigorífica. Revistas Gerenciais, 7(2), 147-154.

Araújo, G. C., \& Mendonça, P. S. M. (2007). 0 processo de adequação a sustentabilidade empresarial. In Anais do IX Encontro Nacional sobre Gestão Empresarial e Meio Ambiente, Curitiba.

Araújo, G. C., \& Mendonça, P. S. M. (2009). Análise do processo de implantação das normas de sustentabilidade empresarial. Revista de Administração Mackenze, 10(2). http://dx.doi. org/10.1590/S1678-69712009000200003

Araújo, G. C., Bueno, P., Sousa, A. A., \& Mendonça, P. S. M. (2006). Sustentabilidade Empresarial: Conceito e Indicadores. In Anais do III Congresso Online de Administração, São Paulo.

Araújo, J. B. (2010). Desenvolvimento de método de avaliação de desempenho de processo de manufatura considerando parâmetros de sustentabilidade (Tese de doutorado). Escola de Engenharia de São Carlos, Universidade de São Paulo, São Carlos.

Argyris, C. (1992). Enfrentando defesas empresariais. Rio de Janeiro: Campus.

Associação Brasileira de Normas Técnicas - ABNT. (2002). NBR ISO 19011:2002: Diretrizes para auditorias de sistema de gestão da qualidade e ou ambiental. Rio de Janeiro.
Associação Brasileira de Normas Técnicas - ABNT. (2008). NBR 1SO 9001:2008: Sistemas de gestão da qualidade: requisitos. Rio de Janeiro.

Azapagic, A. (2004). Developing a framework for sustainable development indicators for the mining and minerals industry. Journal of Cleaner Production, 12, 639-662. http://dx.doi. org/10.1016/S0959-6526(03)00075-1

Bebbington, J., Brown, J., \& Frame, B. (2007). Accounting technologies and sustainability assessment models. Ecological Economics, 61, 224-236. http://dx.doi.org/10.1016/j. ecolecon.2006.10.021

Bernhardi, L., Beroggi, G. E. G., \& Michel, R. (2000). Sustainable Water Management through Flexible Method Management. Water Resources Management, 14(16), 473-495. http:// dx.doi.org/10.1023/A:1011105008526

Bodea, C. N., Elmas, C., T $\square$ n $\square$ sescu, A., \& Dascãlu, M. (2010). An Ontological-Based Model For Competences In Sustainable Development Projects: A Case Study For Project's. Economic Interferences, 12(27), 177-189.

Borella, l. L., \& Naime, R. (2010). Implantação de sistemas integrados de gestão. Inovação, Gestão e Produção, 2(11), 96-103.

Bryman, A. (1989). Research Methods and Organization Studies. Londres: Unwin Hyman. http://dx.doi. org/10.4324/9780203359648

Buson, M. A. (2009). Uma avaliação da sustentabilidade de projetos na fase de planejamento com base nos princípios Lean: Um estudo de caso no segmento de eletrônicos (Dissertação de mestrado). Universidade Federal de Santa Catarina, Florianópolis.

Buson, M. A., Laurenti, R., Rozenfeld, H., \& Forcellini, F. A. (2009). Uma proposta de avaliação da sustentabilidade de projetos na fase de planejamento com base nos princípios lean: um estudo de caso no segmento de eletrônicos. In Anais do Congresso Brasileiro de Gestão de Desenvolvimento de Produto, São José dos Campos.

Campos, V. F. (1994). TQC: gerenciamento da rotina do trabalho do dia-a-dia. Rio de Janeiro: Bloch.

Carvalho, M. M., \& Rabechini Junior, R. (2011). Fundamentos em Gestão de Projetos: Construindo competências para gerenciar projetos: teoria e casos (3. ed.). São Paulo: Atlas.

Carvalho, 0., \& Viana, O. (1998). Ecodesenvolvimento e equilíbrio ecológico: algumas considerações sobre o Estado do Ceará Revista Econômica do Nordeste, 29(2).

Cole, R. (2005). Building environmental assessment methods: redefining intentions and roles. Building Research and Information, 33(5), 455-467. http://dx.doi. org/10.1080/09613210500219063

Coral, E. (2002). Modelo de planejamento estratégico para a sustentabilidade empresarial(Tese de doutorado). Universidade Federal de Santa Catarina, Florianópolis.

Dias, R. (2009). Marketing Ambiental: ética, responsabilidade social e competitividade nos negócios. São Paulo: Altas.

Dow Jones Sustainability Indexes - DJSI. (2012). Retrieved from http://www.sustainability-index.com.

Elkington, J. (1998). Canibals with forks: the triple bottom line of 21st century business. Canadá: New Society Publishers.

Fernández-Sánchez, G., \& Rodríguez-López, F. (2010). A methodology to identify sustainability indicators in construction project management-Application to infrastructure projects in Spain. Ecological Indicators, 10(6), 1193-1201. http:// dx.doi.org/10.1016/j.ecolind.2010.04.009 
Fiksel, J., Mcdaniel, J., \& Mendenhall, C. (1999). Measuring Progress towards Sustainability Principles, Process and Best Practices. Ohio: Battelle Memorial Institute.

Gil, A. C. (2006). Métodos e técnicas de pesquisa social. São Paulo: Atlas.

Global Reporting Initiative - GRI. (2012). Retrieved from www. globalreporting.org.

Hardi, P., \& Zdan, T. (2010). Assessing Sustainable Development: Principles in Practice. Winnepeg: International Institute for Sustainable Development.

Hartig, P. D., Lowrie, D. C., Wever, C. H., \& Lakes, G. (1996). Practical application of sustainable development in decisionmaking processes in the Great Lakes Basin. International Journal of Sustainable Development and World Ecology, 3(1), 31-46, 1996. http://dx.doi.org/10.1080/13504509609469915

Hubbard, G. (2009). Measuring Organizational Performance: Beyond the Triple Bottom Line. Business Strategy and the Environment, 19, 177-191. http://dx.doi.org/10.1002/bse.564

Instituto Ethos. (2006). Conferência Internacional do Instituto Ethos. Retrieved from http://www.ethos.org.br.

Instituto Ethos. (2012). Retrieved from http://www.ethos.org.br.

Jones, B. (2006). Trying harder: Developing a new sustainable strategy for the UK. Natural Resources Forum, 30(2), 124135. http://dx.doi.org/10.1111/j.1477-8947.2006.00165.x

Jones, S., Frost, G., Loftus, J., \& Van Der Laan, S. (2005). Sustainability Reporting: Practices, Performance and Potential. Sydney: Australian Society of Certified Practising Accountants.

Kerzner, H. (2001). Project management - A systems approach to planning, scheduling, and controlling. New York: John Wiley \& Sons.

Kerzner, H. (2006). Gestão de projetos - as melhores práticas (2. ed.). Porto Alegre: Bookman.

Knoepfel, H. (2010). Survival and Sustainability as Challenges for Projects. Zurich: International Project Management Association.

Labuschagne, C., Brent, A. C., \& Van Erck, R. P. G. (2005). Assessing the sustainability performances of industries. Journal of Cleaner Production, 13(4), 373-385. http:// dx.doi.org/10.1016/j.jclepro.2003.10.007

Martens, M. L., Brones, F., \& Carvalho, M. M. (2013). Lacunas e tendências na literatura de sustentabilidade no gerenciamento de projetos: uma revisão sistemática mesclando bibliometria e análise de conteúdo. Revista de Gestão e Projetos, 4(1), 165-195. http://dx.doi.org/10.5585/gep.v4i1.123

Martins, G. A., \& Theóphilo, C. R. (2009). Metodologia da Investigação Científica para Ciências Sociais Aplicadas (2. ed.). Ed. Atlas.

Martins, R. A. (2011). Abordagens quantitativa e qualitativa. In P. Cauchick Miguel (Eds.), Metodologia de Pesquisa em Engenharia de Produção (2. ed.). Ed. Campos.

Mulder, J., \& Brent, A. C. (2006). Selection of Sustainable Rural Agriculture Projects in South Africa?: Case Studies in the LandCare Programme. Engineering and Technology, 28(2), 55-84.

Munck, L., Galleli, B., \& Souza, R. B. (2012). Competências para a sustentabilidade organizacional: a proposição de um framework representativo do acontecimento da ecoeficiência. Produção, 23(3), 652-669. http://dx.doi. org/10.1590/S0103-65132013005000004
O'Dwyer, B., \& Owen, D. (2005). Assurance statement practice in environmental, social and sustainability reporting: a critical evaluation. British Accounting Review, 37, 205-229. http://dx.doi.org/10.1016/j.bar.2005.01.005

Oliveira Filho, J. E. (2004). Gestão ambiental e sustentabilidade: um novo paradigma eco-econômico para as organizações modernas. Domus on line: Revista de Teoria Política, Social e Cidadania, 1(1).

Ortas, E., \& Moneva, J. M. (2011). Origins and development of sustainability reporting: Analysis of the Latin American context. Journal Globalization, Competiveness and Governability, 5(2), 16-37.

Pimenta, H. C. D., \& Gouvinhas, R. P. (2012). A produção mais limpa como ferramenta da sustentabilidade empresarial: um estudo no estado do Rio Grande do Norte. Revista Produção, 22(3), 462-476. http://dx.doi.org/10.1590/ S0103-65132012005000043

Pope, J., Annandale, D., \& Morrison-Saunders, A. (2004). Conceptualising sustainability assessment. Environmental Impact Assessment Review, 24(6), 595-616. http://dx.doi. org/10.1016/j.eiar.2004.03.001

Project Management Institute - PMI. (2008). Um Guia do Conhecimentos em Gerenciamento de Projetos (Guia PMBoK) (4. ed.). Pensilvânia.

Project Management Institute - PMI. (2012). Retrieved from http://www.pmi.org.

Rabechini Junior, R., Carvalho, M. M., \& Laurindo, F. J. B. (2002). Fatores críticos para implementação de gerenciamento por projetos: o caso de uma organização de pesquisa. Produção, 12(2), 28-41. http://dx.doi.org/10.1590/S010365132002000200004

Raven, R. P. J. M., Jolivet, E., Mourik, R. M., \& Feenstra, Y. C. F. J. (2009). ESTEEM: Managing societal acceptance in new energy projects. Technological Forecasting and Social Change, 76(7), 963-977. http://dx.doi.org/10.1016/j. techfore.2009.02.005

Robichaud, L. B., \& Anantatmula, V. S. (2011). Greening Project Management Practices for Sustainable Construction. Journal of Management in Engineering, 27(1), 48-57. http://dx.doi. org/10.1061/(ASCE)ME. 1943-5479.0000030

Rodrigues, 1., Righetti, C. C. B., Facó, J. F. B., Sakuramoto, C. Y., \& Barbieri, J. C. (2005). Estratégias de gestão ambiental nas empresas: análise de um projeto interinstitucional. In R. Rabechini Junior \& M. M. Carvalho. Gerenciamento de projetos na prática: casos brasileiros. São Paulo: Atlas.

Santos, S. F. O. M., \& Hatakeyama, K. (2012). Processo sustentável de produção de carvão vegetal quanto aos aspectos: ambiental, econômico, social e cultural. Produção, 22(2), 309-321. http://dx.doi.org/10.1590/S0103-65132012005000010

Savitz, A. W. (2006). The Triple Bottom Line: How Today's Best-Run Companies Are Achieving Economic, Social and Environmental Success -- and How You Can Too. San Francisco: Editora John Willey \& Sons.

Selltiz, C., Wrightsman, L., Cook, S., \& Kidder, L. (1967). Métodos de Pesquisa nas Relações Sociais. São Paulo: Editora Herder, EdUSP.

Senge, P. M. (1999). A quinta disciplina: arte e prática da organização de aprendizagem (4. ed.). São Paulo: Best Seller.

Shenhar, A., \& Dvir, D. (2007). Reinventing project management: the diamond approach to successful growth and innovation. Harvard Business School Press. 
Silvius, A. J. G., Schipper, R., \& Nedeski, S. (2013). Sustainability in Project Management: Reality Bites 1. PM World Journal, 2(2), 1-14.

Singh, R. K., Murty, H. R., Gupta, S. K., \& Dikshit, A. K. (2012). An overview of sustainability assessment methodologies. Ecological Indicators, 15(1), 281-299. http://dx.doi. org/10.1016/j.ecolind.2011.01.007

Sustainable Measures. (2012). Sustainable Measures: What is sustainability Indicators? Retrieved from www. sustainablemeasures.com

Turlea, C., Roman, T. D., \& Constantinescu, D. G. (2010). The project management and the need for sustainable development. Project Management and the Need for Sustainable Development, 15(3), 121-125.

Veleva, V. \& Ellenbecker, M. (2001). Indicators of sustainable production: framework and methodology. Journal of Cleaner Production, 9, 519-549. http://dx.doi.org/10.1016/ S0959-6526(01)00010-5

Vifell, A. C., \& Soneryd, L. (2012). Organizing Matters: How "the Social Dimension" Gets Lost in Sustainability Projects.
Sustainable Development, 20(1), 18-27. http://dx.doi. org/10.1002/sd.461

Welsch, H. (2005). Constructing meaningful sustainability indices. In C. Böhringer \& A. Lange (Eds.), Applied Research in Environmental Economics. Heidelberg: Physical Verlag. http://dx.doi.org/10.1007/3-7908-1645-0_2

Wilkins, H. (2003). The need for subjectivity in ElA: discourse as a tool for sustainable development. Environmental Impact Assessment Review, 23(4), 401-414. http://dx.doi. org/10.1016/S0195-9255(03)00044-1

World Comission on Environment and Development - WECD. (1987). Our Common Future. 0xford: Oxford University Press.

Yin, R. K. (2005). Estudo de caso: planejamento e métodos (3. ed.). Porto Alegre: Bookman.

\section{Agradecimentos}

Esta pesquisa teve financiamento do CNPq e CAPES.

\title{
Sustainability assessment in project management: an exploratory study of the food sector
}

\begin{abstract}
Despite the increasing diffusion of project management practices, the discussion of issues related to environmental, social and economic sustainability is still incipient. This study aims to assess the integration of sustainability into project management. The methodological approach used was an exploratory study with a qualitative approach, conducted in six projects in the food service companies. Data were gathered through project documents and semi-structured interview with the projects' stakeholders. The results of the pilot tool for the systematic evaluation of sustainability in projects and its practical application are described. The paper concludes that the pilot tool proposed presents a systematic logic with applicability for assessing sustainability in the context of project management. Finally, the results of the assessment show that the economic dimension still overlaps the environmental and social dimensions.
\end{abstract} Keywords

Sustainability. Project management. Sustainability assessment. 


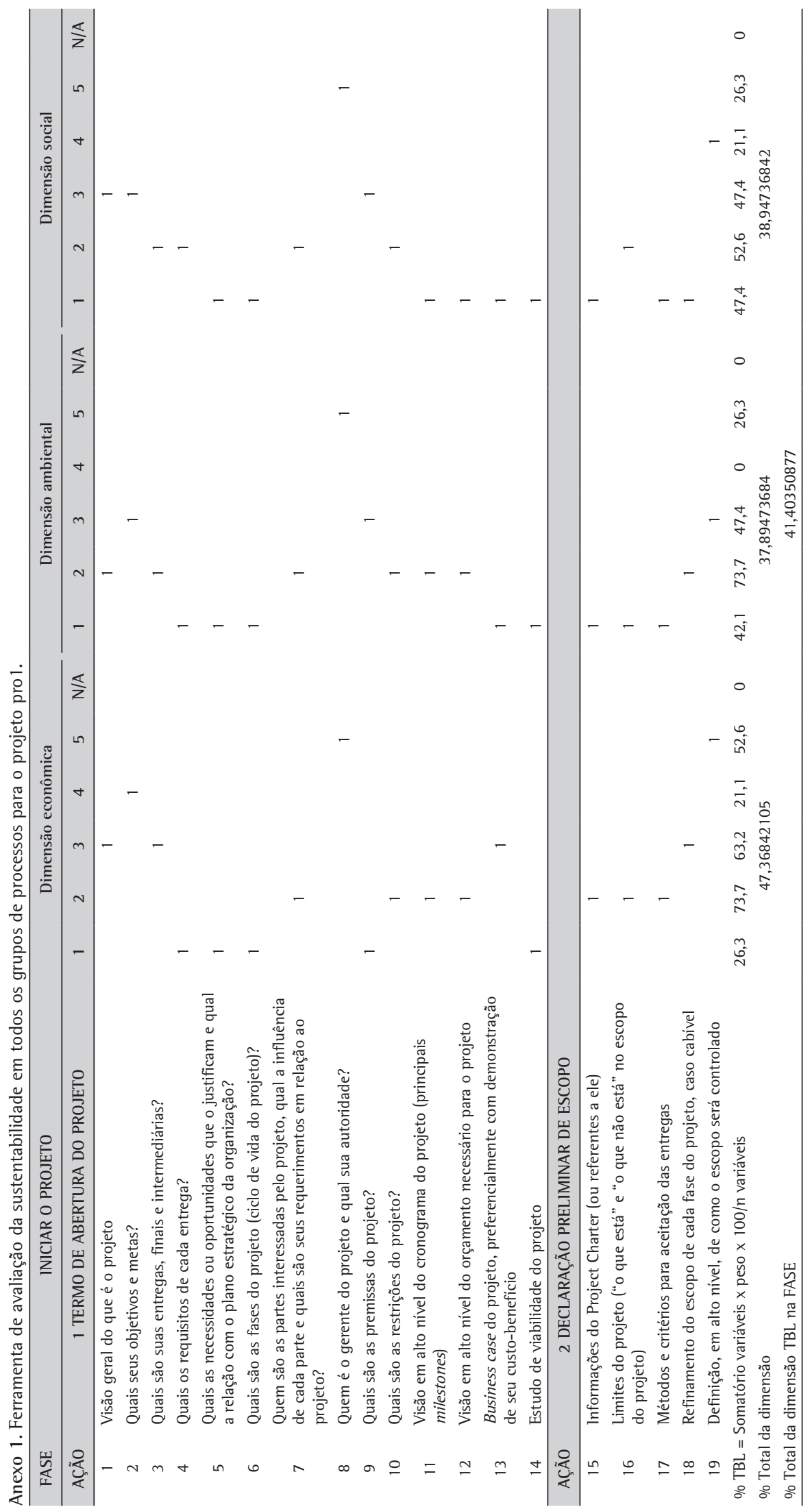




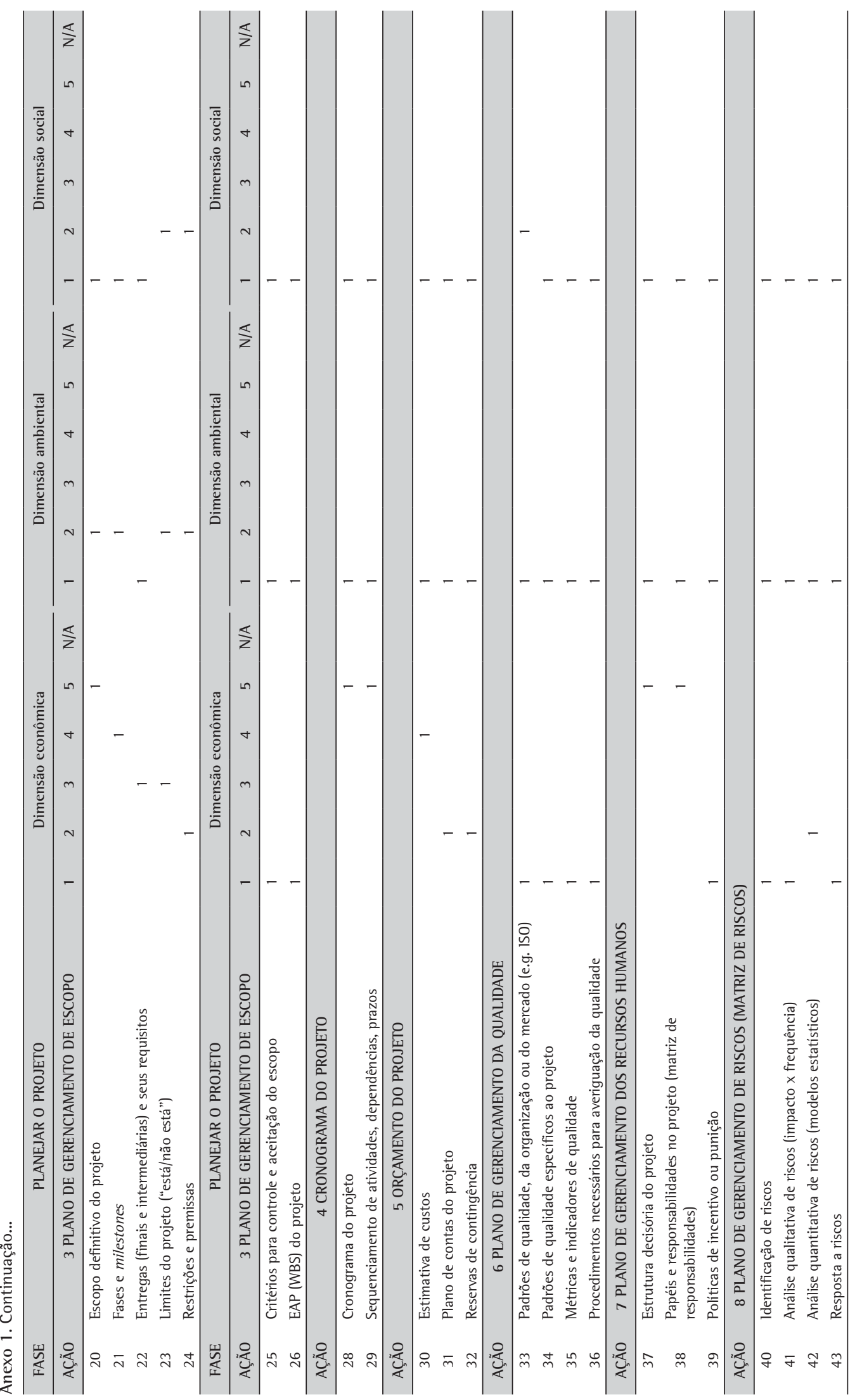




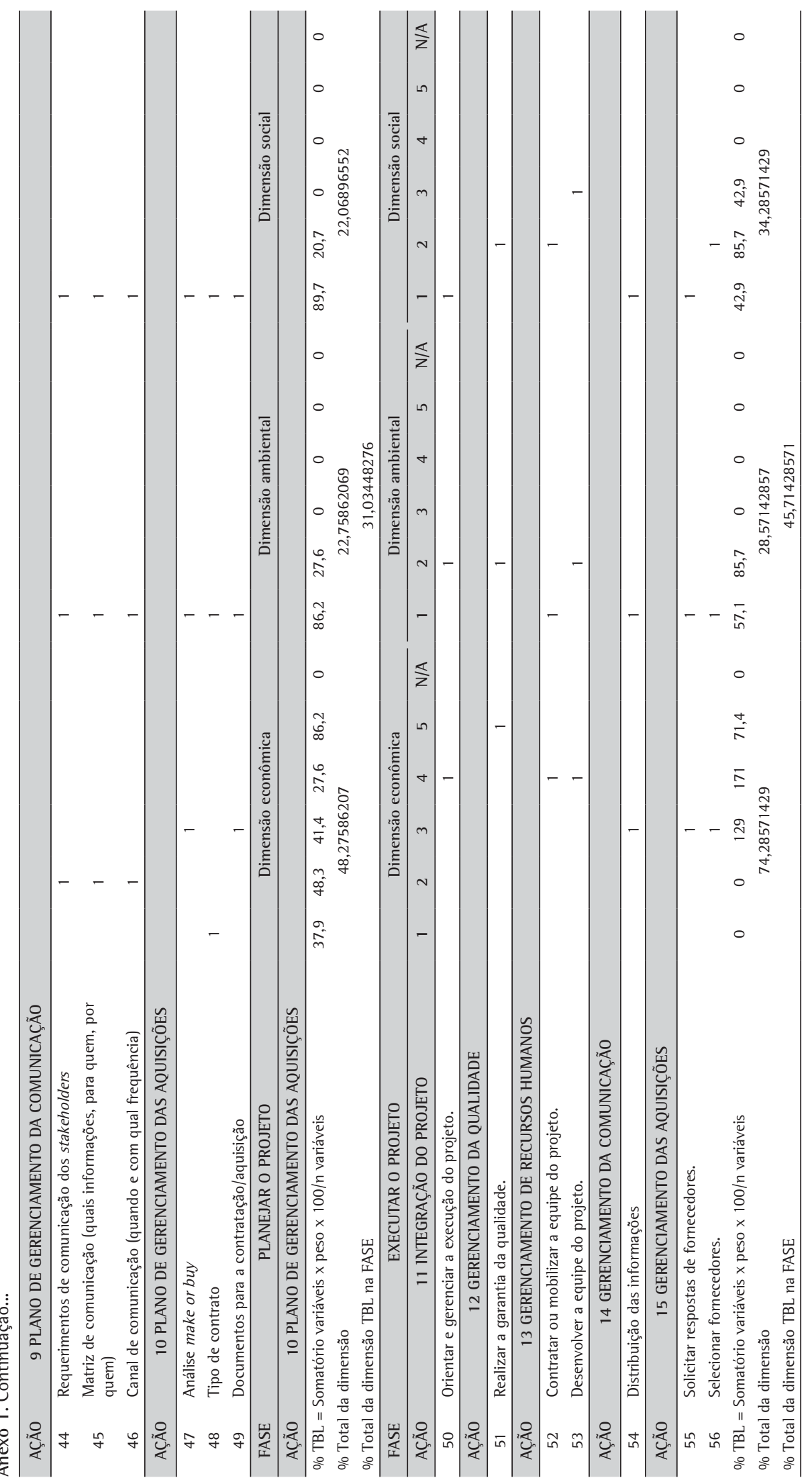




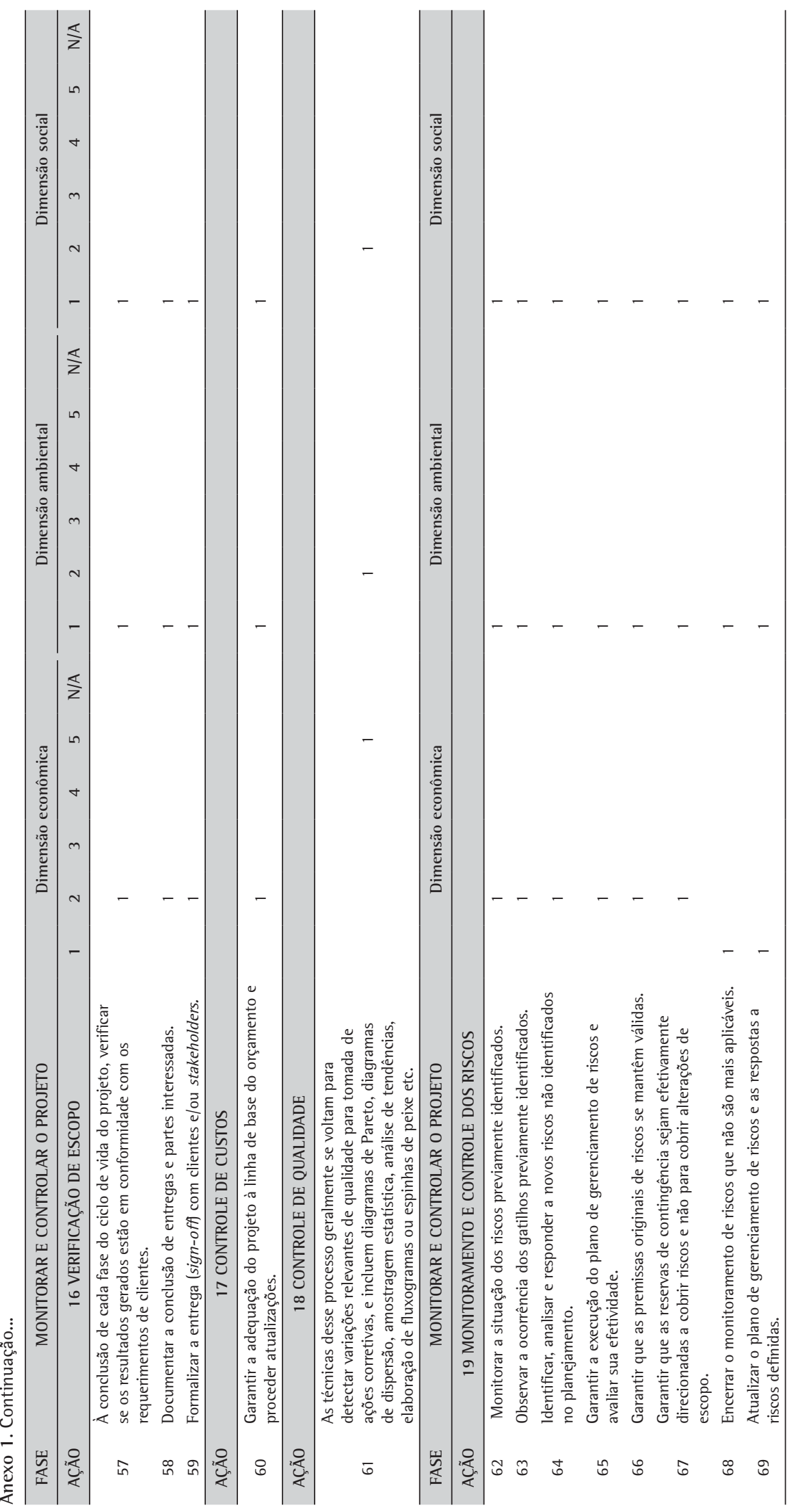




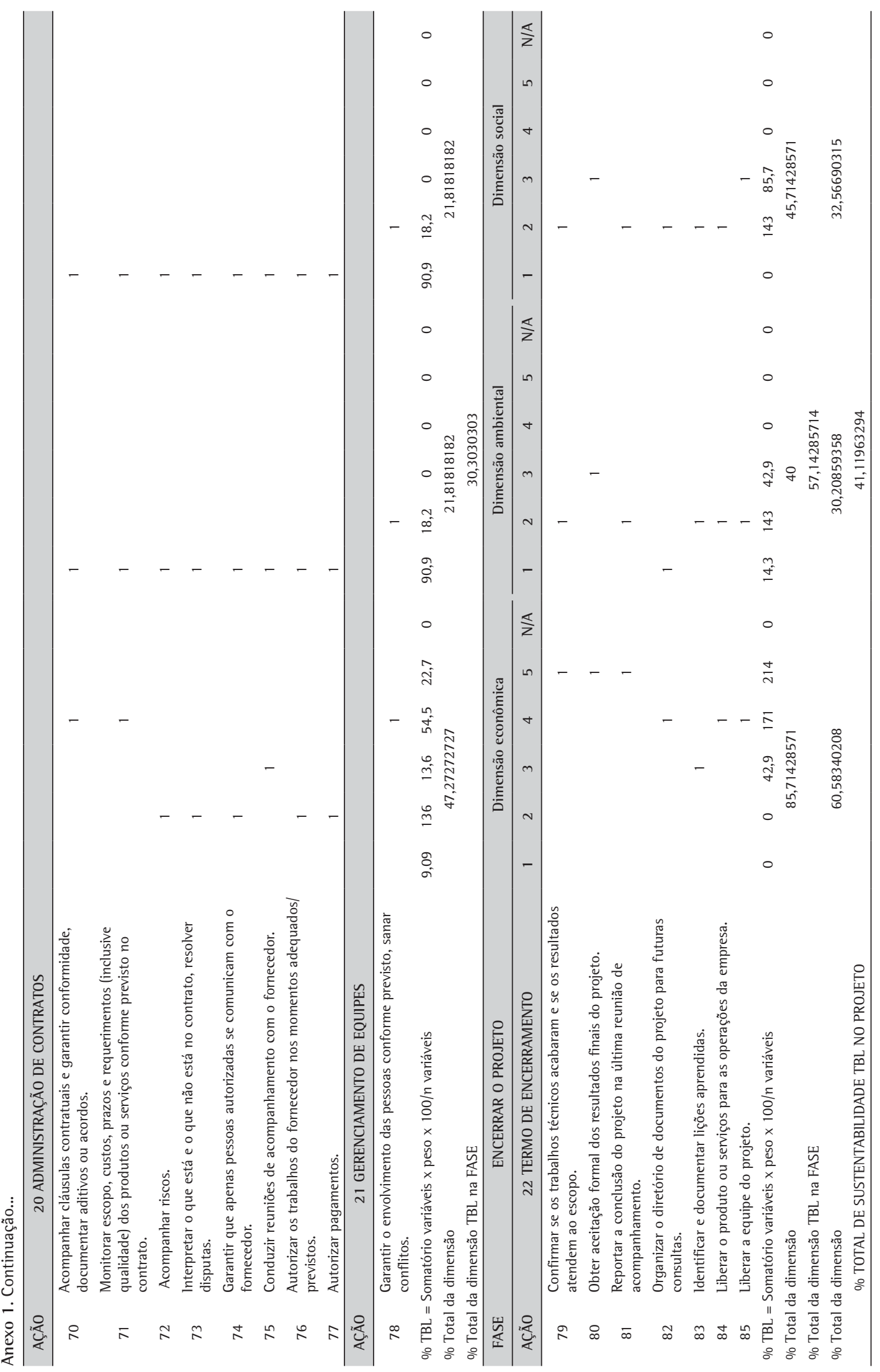

